\title{
Los hermanos Landa Vizcarra
}

\author{
The Landa Vizcarra brothers
}

${ }^{1}$ Gustavo Valcárcel Salas

\section{RESUIIEn}

Los hermanos Tomás y Bernardo Landa se iniciaron como defensores de la causa realista, después militaron en las luchas por la independencia teniendo un destacado protagonismo en las campañas de 1821 y 1823. Tomás fue emisario secreto de San Martín y uno de sus informantes más activo, fue condecorado con la Orden del Sol. Bernardo fue gobernador subdelegado de Moquegua; se une a Miller en 1821, convirtiéndose en su colaborador más eficaz en la brillante campaña del sur. Retorna a Moquegua para preparar la campaña a puertos Intermedios, es apresado y fusilado en 1822 .

Palabras claves: Campaña a puertos Intermedios, Landa, Miller, Moquegua, Torata.

\section{ABSTRACT}

The brothers Tomás and Bernardo Landa initiated as defenders of the royalist cause, afterwards they militated in the fights for the independence and played an outstanding role in the campaigns of 1821 and 1823. Tomás was San Martín's secret emissary and one of his most active informants, he was awarded the Orden del Sol. Bernardo was subdelegated governor of Moquegua; he joined Miller in 1821, becoming his most effective collaborator in the brilliant southern campaign. After returning to Moquegua to prepare the campaign to puertos Intermedios, he was captured and shot in 1822 .

Keywords: Intermediate Ports Campaign, Landa, Miller, Moquegua, Torata.

${ }^{1}$ Archivo Regional de Moquegua. Moquegua, Perú.E-mail: gusvals@gmail.com

Presentado: 26/02/2021 Aprobado: 06/04/2021 


\section{La familia Landa}

Los hermanos Tomás y Bernardo Landa fueron esclarecidos precursores de la independencia nacional. Tuvieron una destacada participación en las campañas del sur ideadas por San Martín, quien llegó a depararles la confianza de encomendarles misiones de gran responsabilidad y mantuvo con ellos una sostenida e interesante comunicación epistolar. Sin embargo, siguen siendo desconocidos o rodeados de la confusión por la historia oficial.

Fueron hijos del matrimonio del vasco Vicente Landa con María Josefa Vizcarra, de linaje moqueguano tan antiguo como ilustre.

Tomás fue bautizado el 5 de mayo de 1770, a los tres días de nacido, con el nombre de Juan Tomás², fue el hijo mayor. A los dieciocho años viajó a estudiar a la Universidad de Córdova (Argentina). Vivió tres lustros en esta ciudad, en una época en la que ya se gestaban las ideas libertarias en las Provincias Unidas del Río de la Plata. A principios del 800 ya era vecino de Moquegua y alternaba su estadía con frecuentes viajes a Lima. En 1809 era residente en Lima.

Bernardo $^{3}$ nace en 1781. A los veintiún años contrae matrimonio con Viviana de la Flor Hurtado ${ }^{4}$ Se dedicó a conducir la bodega de Calaluna, que arrendó a Isabel Vascones, viuda de Juan de Pomareda.

\section{Moquegua en 1800}

$\mathrm{Al}$ iniciarse el siglo XIX la villa de Moquegua con cerca de ocho mil habitantes era geográfica, política y económicamente una de las principales del sur. Su economía estaba basada en el cultivo de la vid y el olivo. Había una estrecha y permanente vinculación con el Alto Perú, principal mercado de los afamados vinos y aguardientes, del aceite de olivo que se producía en el valle de Ilo, de una diversidad de frutas, así como de la mercadería que ingresaba por el puerto; a cambio de minerales, tubérculos, lana, ganado equino y mular, etc., conducidos por un continuo tráfico de arrieros.

El Colegio Franciscano de Propaganda FIDE era un foco cultural que se proyectaba hasta la selva en misiones evangelizadoras y daba sólida formación a la juventud local y regional, y muchos continuaban su educación en las universidades de Chuquisaca y Córdova. Este plantel, que fuera fundado en 1711 como jesuita, ahora era administrado por frailes de origen español en su mayoría, quienes juraron fidelidad a la corona cuando España fue invadida por Napoleón, juramento que fue reiterado durante las guerras por la emancipación americana. Si bien entre sus integrantes había religiosos que eran decididos partidarios de las ideas libertarias (eran los menos) que provenían de los claustros arequipeños dirigidos por el liberal Chávez de la Rosa, la mayoría eran consecuentes con su nacionalidad española y por lo tanto resueltos partidarios del rey.

Desde los albores del siglo XIX el continente era sacudido continuamente por los movimientos revolucionarios. Al producirse la revolución de la Provincias Unidas del Río de la Plata en 1810, sus líderes e ideólogos consideraron siempre que para consolidarla no había otra alternativa que expandir la lucha y liberar al Alto y Bajo Perú, bastión económico y militar de Sudamérica.

Para promover la rebelión, llegan mensajeros secretos a Arica, Tacna y Moquegua, a la que consideran zona estratégica. Como consecuencia de ello, Zela se levanta en Tacna en 1811 en un intento de apoyar a Castelli que avanzaba por el Alto Perú. Ese mismo año, los negros del valle de Moquegua, al no tolerar más la afrenta de la esclavitud, proyectaron sublevarse el día de carnaval. Fracasado el intento los cabecillas fueron ejecutados.

\footnotetext{
${ }^{2}$ De los dos hermanos que tomaron parte en las guerras por la independencia es el menos conocido, siendo su trayectoria la más notable y reconocida.

${ }^{3}$ Bautizado a los ocho meses de edad el 18 de abril de 1782. Nace posiblemente el 20 de agosto de 1781, día de San Bernardo.

${ }^{4}$ Bautizada a los dos días de nacida el 3 de diciembre de 1778 como María Viviana. Fue hija de José Domingo de la Flor y de María Hurtado Fernández Dávila.
} 


\section{Bernardo Landa, realista}

Vinculado a las antiguas familias locales que presumían de su nobleza, se sentía solidario con la causa realista. En 1809 le confían la empresa de ir a la ciudad de Arequipa en una expedición de 200 hombres en la que se comportó con la mayor honradez, entonces como sargento de primera clase en la infantería de las milicias de la villa de Moquegua. Considerando su eficiente comportamiento, el subdelegado Francisco de Paula Páez le confía la comisión de llevar 200 caballos para el ejército acantonado en el Desaguadero, misión que se ofrece cumplir “[...] sin salario, estipendio, ni gratificación alguna, y convino gustoso y se encargó de la compra de algunos caballos [...]”" (Archivo General de Indias [AGI], Audiencia de Lima 760, N. $\left.{ }^{\circ} 8-4\right)$.

Para sofocar al movimiento platense, que buscaba expandirse por la región, José Manuel de Goyeneche parte al Alto Perú. En las victoriosas acciones de Zepita en marzo de 1811, tuvo como eficiente colaborador al teniente Bernardo Landa, quien desde 1809 ya prestaba sus invalorables servicios al ejército realista, y en las acciones de Potosí del año siguiente, zona andina que conocía bien por trajinarla en su constante negocio y comercio de aguardientes y otros efectos. Por su eficiente apoyo, en 1812 se le premia con el grado de teniente en la primera compañía de fusileros de las milicias urbanas del regimiento de Moquegua.

Su familiaridad con los caminos y el manejo constante del arrieraje lo convierten en un personaje solicitado para las misiones de confianza. Una vez más, Goyeneche lo busca en 1812 y dispone que vaya a los partidos de Tacna y Moquegua a colectar todo el número de mulas cargueras con sus aperos, arrieros y peonaje respectivo y los conduzca a Potosí. Después, se presenta como voluntario para luchar contra los insurgentes porteños y se ofrece a ir hasta Buenos Aires. La misión lo llevó hasta el Tucumán, donde tomó parte en el combate del 24 de setiembre de 1812 cuando las fuerzas patriotas del ejército de Manuel Belgrano derrotaron a las españolas de Pío Tristán que las doblaban en número (AGI,id.).

Recorre reiteradamente la zona sur recogiendo mulas, arreos y peonaje necesarios para apoyar las fuerzas reales afincadas en el Alto Perú. El reconocimiento que recibe por esta acción es elocuente, como lo acredita el informe de

José Manuel de Goyeneche y Barrera [sic], gobernador intendente comandante general de las armas de la provincia del Cusco, presidente interino de su real audiencia, etcétera, etcétera, certifico que don Bernardo Landa [...] ha conducido de aquélla [Moquegua] a este ejército gratuitamente, comisionado por su gobernador sub delegado, dos partidas de caballos, desempeñando estas comisiones con el mayor esmero, cuidado y celo [...] se le dan las gracias en nombre de Su Majestad. Desaguadero, 9 de mayo de 1811. (AGI,id.)

Después, le confían como comandante en jefe la felice expedición que se destinó para combatir a los rebeldes tacneños, con quienes se enfrenta en Calana y Pachía.

Posteriormente, se presenta como voluntario para combatir la rebelión del "inicuo francés Enrique Paillardelle". La acción tuvo lugar en Camiara; la columna realista estuvo al mando de José García de Santiago, coronel de los reales ejércitos y comandante en jefe de las armas del rey, enviado especialmente para la pacificación del pueblo de Tacna. Bernardo Landa participa en la división que partió de Moquegua bajo la dirección del capitán Luis de Pomareda, entonces se le otorga la responsabilidad de conducir una guerrilla de veinticinco hombres en compañía del subteniente Marcelino Puertas, siendo su arrojada intervención decisiva, en la que puso en riesgo su vida, consiguiendo de este modo la victoria (Eguiguren, 1961, p. 49 y sigs.), (Archivo Regional de Moquegua [ARM], Jph. Fernández Dávila 1812, f. 240). 


\section{Independencia de Moquegua-1814}

A pesar de estos tempranos reveses, las luchas por la libertad se hacían incesantes. En 1814, fue la formidable rebelión de Pumacahua y los hermanos Angulo, que estalló en el Cusco. Como apoyo a Pumacahua cuando ingresa victorioso a Arequipa los primeros días de noviembre, el día 11 Moquegua se adhiere a la revolución proclamando su independencia "a influjos del caudillo Landa", que contó con el apoyo de la fuerza militar que tenía a su mando, como lo testimonia en sus memorias Joaquín de la Pezuela (2011, p. 92) ${ }^{5}$. Al ser debelada la insurrección cusqueña, huyendo del altiplano se refugia en Moquegua el líder revolucionario presbítero Ildefonso Muñecas, junto a José Astete que estuvo acompañado de su mujer y del argentino José Cherveches. Estos dos últimos fueron entregados en diciembre por Landa, disuadido por el obispo Luis Gonzaga de la Encina que se encontraba de visita pastoral y que astutamente lo convence para traicionar la revolución. Los apresados poco después serían fusilados en Arequipa. El cura Muñecas fue ocultado por el presbítero Hilario Hurtado, para luego fugar rumbo al Alto Perú. El obispo calificó a Landa de "ángel tutelar de Moquegua, defensor de su dignidad y opresor de los cusqueños revolucionarios" (Cf. Leguía, 1972, p. 102) (Paz-Soldán, 1956, p. 279), (AGI, op. cit.).

El ayuntamiento y pueblo de Moquegua, reunidos en Cabildo abierto el 10 de diciembre de 1814, tomaron en cuenta las acciones ocurridas el día anterior, en la que el pueblo conducido por Landa combatió a los cusqueños, que apoyados del estruendo de la artillería que tenía en sus manos Cherveches, se impuso inicialmente. Oportunidad en la que Landa contó con el concurso del regidor Agustín Zapata y numerosos labradores que lograron apoderarse de esta artillería con solo dos hombres muertos y pocos heridos, tomando dieciocho prisioneros. Deliberaron que por haber conseguido que "el partido de Moquegua se volvió a la obediencia por la contrarrevolución que hizo el mismo Landa", como lo indica Pezuela (2011, p. 94), en sus memorias admitieron el pedido que por aclamación hizo el pueblo en este Cabildo abierto, y Landa fue premiado con el nombramiento de gobernador subdelegado y comandante militar de Moquegua y puerto de Ilo. También había sido designado capitán del Ejército del Alto Perú (AGI op. cit.).

\section{Bernardo Landa, subdelegado}

Desde su cargo se convierte en tenaz defensor realista, siempre asesorado y sostenido por el obispo Gonzaga de la Encina, a quien recurría con frecuencia en busca de sus consejos, escribiéndole cada vez que partía en alguna misión: "Venerado señor [...] si vuestra señoría ilustrísima me considera útil en esta expedición, impártame las órdenes que estime oportunas".

Landa en una ocasión fue requerido para apoyar al importante batallón realista de Gerona que se dirigía de Puno a Moquegua, en previsión de las continuas revueltas que se promovían desde las provincias rioplatenses, que consideraban a Moquegua como lugar estratégico para combatir la rebelión. Se le instruye

que debe prevenir sin demora cuarteles para la tropa y alojamientos para los oficiales, bajo el concepto de que la fuerza de dicho batallón pasa de mil hombres, que en los puntos de Chilligua, Cañagual, Alto de Baldivia y en esa misma villa debe aprontar leña, carne, pan y los demás auxilios que permitan las distancias y las proporciones locales. (Latin American Mss, Peru, Manuscripts Department, Lilly Library Indiana University, documento facilitado por Teresa Cañedo - Argüelles)

\footnotetext{
${ }^{5}$ Las memorias de Pezuela también fueron publicadas por F. Denegri Luna en La Revista Histórica (1954), tomo XXI, en la página 257 indica que "El 11 se revolucionó Moquegua a influjos del Caud. ${ }^{\circ}$ Lanza [...]”. En el prólogo explica que el original de la primera parte se encuentra en Santiago de Chile, de donde lo obtuvo. También la publicó en 1974 en la Colección Documental de la Independencia del Perú, t. XXVI, vol. 1, pág. 241 sin incluir las notas explicativas a pie de página de la primera edición. Por su parte, Ortemberg y Sobrevilla comunican que había otro manuscrito en Santander, España, con algunas pequeñas pero sustanciales variantes, y es la que publican; en esta edición (2011: 92) aluden a Landa en dos ocasiones. Por ser más completa nos merece más crédito que la que se encuentra en Santiago de Chile, que es la versión publicada porDenegri.
} 
Dedicó sus "cuidados, fatigas y desvelos animado de sentimientos de amor al lugar de mi nacimiento, que hoy gobierno, y fidelidad al soberano, no he omitido cuantos medios me han parecido oportunos para la mayor seguridad de aquella villa, y a la quietud y sosiego de sus habitantes" (AGI op. cit). Restableció la contribución de los tributos indígenas en todo el partido, que habían sido derogados por la progresista constitución española de 1810 la misma que fuera abolida dos años después.

Por orden del intendente Moscoso, en noviembre de 1815, se desplaza a combatir la rebelión de Tarapacá, liderada por el cusqueño Julián Peñaranda y José Choque (suelen llamarlo Choquehuanca) que mantenían estrecha comunicación con Rondeau que con su ejército avanzaba por el Alto Perú, y que días después sería batido en Viluma (Wiloma, para otros Sipe Sipe) en Cochabamba. Aquí Landa permaneció más de dos meses cumpliendo exitosa y fielmente el encargo. Viajó sin prest, por lo que mientras duró su estadía se vio obligado a erogar 500 pesos de su propio peculio para mantener a los hombres bajo su mando, "reusando de veras ser graboso al real haber".

A su retorno a la villa de Moquegua, era tan reconocida su lealtad al rey, que se le confía la vigilancia de "los prisioneros de la gloriosa acción de Wiloma, a quienes mantengo en la mayor custodia, sin reparar en gastos", como informa a fines de febrero de 1816 al virrey don Joaquín de la Pezuela, dándole cuenta también del envío que hizo a Puno de 100 hombres, auxilio pedido por el intendente de aquella ciudad, que se veía constantemente amenazada desde las Provincias Unidas del Río de la Plata. Relato que hace "en virtud del ciego obedecimiento con que miro los superiores preceptos de vuestra excelencia" (Archivo General de la Nación [AGN], GO.CO 211.3332; AGN, GO.CO 2211.3354; Vargas, 1932; Castro, 2018).

Pesaría sobre su conciencia haber traicionado el movimiento y ser el responsable del fusilamiento de dos líderes, esto explicaría el por qué trata de alejarse reiteradamente de Moquegua. Gestiona un empleo en 1816 y solicita al gobierno "cualesquier negocio que le sean útiles y convenientes". Tres años después, insiste en su petición y otorga poder al conde de Maule, vecino de Cádiz, para que presente ante el rey "pretendiendo empleos y gracias que sean de su real agrado". Sus ruegos no fueron atendidos, no obstante que el virrey Pezuela eleva el pedido a la corte indicando que los

[...] méritos y servicios que tiene hechos a Su Majestad los que practicados con un acreditado celo y recomendable lealtad, con repetidos riesgos de su vida, con una loable generosidad y aún con pérdida de sus intereses como lo comprueban los documentos instructivos que acompaña, le hacen en mi concepto acreedor a la consideración benéfica del soberano [...]. (AGI, Audiencia de Lima 760, No. 8 -4)

El desempeño de tan importante cargo no estuvo exento de dificultades. Ya en 1816 tuvo problemas con el acaudalado José Carlos Mendoza quien desafía su autoridad; Landa eleva su queja a Joaquín de la Pezuela, entonces excelentísimo señor virrey del Perú, y le dice "que a la sombra de sus bienes de fortuna, abasallase la justicia que se asistía, lo repelí en medio de la desigualdad de haberes que entre él y yo se veía [...] recibiendo diariamente insultos de ese potentado", y promete "daré ese asunto en las cenizas del olvido" pues consideraba que las acusaciones que se le hacían "eran hablillas faltas de caridad y religión". Eran recíprocas las denuncias de agravios de una enemistad iniciada tres años atrás, cuando Landa era el jefe militar de la villa, entonces fue querellado por "graves injurias con que lo había atropellado". J. C. Mendoza era casado con María Martina Fernández Cornejo, ambos de muy ilustre prosapia y serían reconocidos como generosos benefactores de la ciudad (AGN, RA-CR 4128.1560). En enero de 1817 Pedro Gómez, entonces vecino de la villa, acusa a Landa de haberse apropiado de 492 pesos y 4 reales. Rechaza la calumnia y dirigiéndose al coronel Juan Mariano de Goyeneche, le explica que lo usó "para sueldos de la fuerza acuartelada, y de la que tengo dada en cuantas a la superioridad". Dificultades que no serían las únicas. Dos años después se queja de "[...] varios encuentros injustos que me ha preparado este Cabildo, de los que he huido el bulto sin embargo de que soy el blanco de la injusticia [...]”" (Biblioteca Nacional del Perú [BNP], D 11885). Ahora la queja es de Manuel Rubio, vecino de la villa que se desempeñaba como juez diputado de Comercio, se queja de las trabas que le imponía el subdelegado Landa para ejercer como albacea 
testamentario del español José Otero. Hace ver de los "muchos y graves casos que convencen de la opresión y capital enemistad del subdelegado" Landa contra él; recalca que durante su gestión también tuvieron dificultades el Dr. Juan Cabello, José Santiago de la Flor y Pedro Gómez "que no han escarmentado ni contenido al subdelegado". Pide que Landa no se entrometa en todos sus negocios, "con sus parientes dentro del cuarto grado, ni con sus domésticos ni dependientes", por el encono y hostilidad declarada con que procede Landa "sin perjuicio de la capitulación que ha omitido por consideración al corto tiempo que resta a Landa para concluir su destino y dar la residencia que desde ahora pido para que se le detenga en la villa, hasta que se formalice con arreglo a las leyes". En marzo de 1820, le es concedida la petición para que Landa se inhiba perpetuamente en estos casos (AGN, RA-CI 4 168.1723).

En el ejercicio de la subdelegación, Bernardo Landa se preocupó por los principales problemas que afectaban a los pobladores. Nuevamente recurre al influyente coronel del ejército Juan Manuel de Goyeneche para "suplicarle interponga otra vez su poderosa mediación para conseguir del señor gobernador intendente el alivio de infinitos miserables como son en el día casi todos los habitantes de esta villa" [Carta de B. Landa del 20 de julio de 1818 a Juan Manuel de Goyeneche (BNP, Encina (A))].

La actividad económica de la villa descansaba en el comercio del vino y aguardiente, que desde fines del siglo anterior eran sostenidamente afectados por impuestos. El gravamen resultaba oneroso para una población que veía cada vez más escasos sus caudales. Esta economía ya agredida era menoscabada aún más con las exacciones producidas durante las continuas luchas por la independencia. El virrey Joaquín de la Pezuela escribe el 24 de marzo de 1817 “[...] previne a Portocarrero y al subdelegado de Moquegua, Landa, para que acordasen de un modo conciliatorio cómo mantener el batallón nuevamente formado en Arica, por medio de una voluntaria contribución de los habitantes de ambos partidos [...]" (Pezuela 1947, p. 126).

Ante esa penosa situación es que actúa Landa, manifestando nuevamente su preocupación y escribe a Goyeneche intercediendo por sus paisanos

[...] ya sabrá V. S. los formidables impuestos al aguardiente, único ramo de su fomento. Sabrá los ingentes capitales a que están afectos estas fincas, y sabrá también la manifestación que ha hecho de su miseria indicándola con un plan documentado que demuestra el alcance de más de treinta y siete mil pesos que sale cada año contra este valle, sobre lo que habiéndose ahora nuevamente impuesto por la junta de arbitrios de esa capital de provincia un dos y medio por ciento a los productos rústicos, y viéndose la imposibilidad en que están estos hacendados de poderlo pagar se representó esta por el procurador general de esta villa al excelentísimo señor virrey, quien ha ordenado pase esta misma representación por mano del propio procurador al señor gobernador intendente para que se vea si se puede reemplazar este arbitrio con otros que puedan tomarse en la provincia. El miserable estado de Moquegua exige la mayor compasión, intereso pues para su alivio, la humanidad de V. S. con cuya protección espero ver libre de este sobrecargo a unos vecinos que aún sin el ya no pueden subsistir, y a quienes sus fincas ya de nada les aprovecha. (BNP, D 11885)

En otro momento, a propósito de este pedido, le dice "nací en esta villa, palpo y veo su mísera situación, y mi sensibilidad anhela y desea su efecto que no dudo conseguir con la mediación de V. S." id.

Mientras tanto, en la capital también se vivían días de zozobra. En 1818, fracasó la toma de los castillos del Real Felipe del Callao, conjura que fue encabezada por José Gómez, José Casimiro Espejo y el joven médico moqueguano Nicolás Alcázar quienes fueron ejecutados. También estuvieron implicados los igualmente moqueguanos Carlos Zabárburu y el comerciante Lorenzo Valderrama. Este último y Gómez lograron huir a tiempo, conducidos por Tomás Landa, que "con un patriotismo decidido acompañó a Valderrama en su peregrinación a Chile por el desierto de Atacama” (Herrera, 1862, p. 271), (Leguía, 1972, t. II, p. 307 y sigs.).

"Germán Leguía considera a Tomás Landa como “otro de los comprometidos con Gómez" “en la atrevida empresa de la captura de los castillos del Callao” (Leguía 1972, p. 305 - 307). En el libro de Gálvez (1909) no figura Landa en la relación de los implicados en esta acción. 
A pesar de estos avatares, Tomás Landa logra reintegrarse a su suelo natal figurando como vecino de la villa de Moquegua al año siguiente, en octubre de 1819.

En la villa de Moquegua la intranquilidad era permanente. Los emisarios secretos de las Provincias Unidas del Río de la Plata visitaban constantemente la región. Los bonaerenses desde un principio ya consideraban en sus proyectos una expedición marítima que debía desembarcar por Ilo, avanzar hasta Moquegua y liberar a los esclavos e incorporarlos al ejército libertador.

Este estado de cosas demandaba de las autoridades un esfuerzo para incrementar y mantener en alerta un numeroso ejército que pudiera conservar el orden y defender la causa del rey. Y todo ello cargado sobre la cada vez más empobrecida economía local.

Que la situación económica de Moquegua estaba afectada por las continuas exigencias para mantener los ejércitos en campaña, y que no pasaba por sus mejores momentos, lo testimonia el hecho de que cuando José de la Serna llega a Arica el 7 de setiembre de 1816 para asumir el cargo de virrey, acompañado de un numeroso séquito,...

era tal la penuria del erario que el general en jefe y su comitiva, tuvieron que defenderse en Arica por falta de recursos: lo mismo sucedió al batallón "Gerona" que desembarcó allí procedente de Panamá; y fue preciso para que este cuerpo y el general saliesen para el Alto Perú, se exigiera en Moquegua un empréstito forzoso en que se admitieron alhajas de uso de varias señoras. (Mendiburu, 1934, p. 140)

En la Memoria que Manuel Vidaurre eleva al rey el 12 de abril de 1817 decía que...

en Moquegua, villa opulenta, las contribuciones extraordinarias y sin proporción, la falta de mulas necesarias a la conducción de sus aguardientes a La Paz, Oruro y Potosí, los reduce al estado deplorable de no poder levantar sus cosechas. Pierde V. M. por mala política de estos gobernadores, los grandes derechos que aguardientes y vinos producían en aquel rico partido, y los propietarios anuncian en sus voces, en sus rostros, en sus cartas el estado en que se hallan de desesperación. (Vidaurre, 1971, p. 276)

Este mismo autor más adelante agrega:

¿Qué dirá el comercio con los donativos y préstamos valiosos que ha hecho? ... ¡Qué la opulenta villa de Moquegua, de donde se extraían 50,000 quintales de aguardiente que importaban, a 10 pesos, medio millón, sin incluir vinos, y hoy por falta de mulas no se pueden vender a ningún precio! (Vidaurre, 1971, p. 337)

Aun así, en medio de todas estas previsiones, ilustres vecinos ya militaban activamente en las intrigas y revoluciones por la libertad. La lucha por la independencia se había generalizado y era incontenible.

El subdelegado B. Landa toma parte en las precauciones realistas y delata a conspiradores, combate revueltas patriotas y es un vigilante permanente de los intereses de la corona.

Poco después, en 1819, enviado por el gobierno de Bernardo O'Higgins, "un comerciante chileno, Rafael García (a) «Francisco Zelaya» entró en contacto con los patriotas de Tacna y Moquegua [...] [con] el futuro general Mariano Portocarrero, para quien llevaba un oficio del general Guido; y con don Bernardo Landa, a quien puso en comunicación con O'Higgins y San Martín” (Leguía, 1972, op. cit. p. 461). 


\section{Tomás Landa, emisario secreto}

En 1820 San Martín envía de Valparaíso la goleta “Terrible” en la que, entre otros patriotas, viajan Tomás Landa, Lorenzo Valderrama y Nicolás González, natural de Salta ${ }^{7}$. Desembarcan en las costas de Arica, fingiendo ser arriero T. Landa se dirige a Tacna y pasa a Moquegua donde lleva a cabo una diligente labor. Como resultado de esta misión envía a San Martín un valioso informe socio-económico de la región (Cf. Herrera, 1862, op. cit., p. 179).

Da a conocer una relación de vecinos de estos lugares identificando a las autoridades, la ocupación, posición social, informando sobre su capacidad económica, las posibilidades de contar con ellos por su patriotismo.

En setiembre de 1820 el Libertador arriba a Paracas y T. Landa se reúne con él en Supe. Al mes siguiente, dispone que Landa en compañía de Lorenzo Valderrama parta a Valparaíso en misión de confianza ante el gobierno de Chile en busca del apoyo de ese país para el envío

de una expedición de quinientos hombres al menos, sobre aquella costa [Moquegua], cuyos habitantes son quizá de los más decididos por nuestra causa, produciría el doble efecto de privar al enemigo de los recursos que ella puede proporcionarle, y dar un golpe a la opinión que sea tanto más impresivo cuanto es menos esperado. (Senado Argentino [SA], 1960, p. 15065) (Leguía, 1972, op. cit., p. 211)

\section{DOCUMENTO QUE MANIFIESTA LOS SUJETOS DECIDIDOS AL PARTIDO DE LA PATRIA EN TACNA Y SU JURISDICCIÓN, VALLE DE SAMA, VALLES DE SITANA Y LOCUMBA, Y VILLA DE MOQUEGUA}

El subdelegado, coronel de milicias, don Mariano Portocarrero Calderón, inclinado a la patria de poco tiempo a esta parte.

El coronel de milicia urbanas de caballería del partido de Tacna, don Tomás Moreno Chocano: chileno, casado con doña Bernarda Cornejo, muy patriota esta última, más que el marido, por ser este algo tímido. Es hacendado en el valle de Locumba.

El teniente coronel don Rafael Gabino de Barrios. Patriota, pues actuó en la insurrección de 1811, pero pusilánime. Hacendado en Tacna, con fortuna más que regular, casado, sin hijos.

El teniente de compañía don Francisco de Paula Alayza, decidido patriota, de espíritu elevado y con algún influjo. Casado, de poca fortuna.

El oficial mayor de la aduana don Lorenzo de las Infantas. Lo dicho respecto del anterior, pero con mayor espíritu para cualquiera empresa. Casado, con familia, sin fortuna.

El teniente de compañía don Manuel Caderón de la Barca. Actuó en 1813 al lado de los hermanos Paillardelle. Por su patriotismo se ha visto más de un año en padecimientos de prisiones rigurosas. Casado y escaso de fortuna.

El gobernador cacique del pueblo don Toribio Ara, patriota decidido, con influjo, casado, con bastante familia y con más de regular fortuna.

D. José Rosa Ara, hijo del anterior y su heredero en el cacicazgo de Tacna. Buen patriota. Actuó en 1811 en connivencia con Zela, y en 1813 en connivencia con Paillardelle y Calderón de la Barca. Casado y con familia.

Doña Antonia Ara, hermana del anterior. Patriota sin embozo. De buenas barbas. Muy festejada.

\footnotetext{
${ }^{7}$ José Hipólito Herrera (1862, p. 179) menciona estos nombres indicando que fueron en la goleta "Libre”. Pezuela (op. cit. p. 746), señala que el 17 de julio salió de Valparaíso la goleta "Terrible" con el objetivo de introducir espías. El 24 de julio desembarcaron en la ensenada de Camarones los espías Tomás Landa, hombre de edad, hermano del subdelegado actual de Moquegua, N. González y N. Valderrama. ${ }^{8}$ Publicado en Historia de las insurrecciones de Tacna por la independencia del Perú por Rómulo Cúneo-Vidal (Librería e imprenta Gil, Lima, 1921). Al desconocer el nombre del autor, Cúneo lo llama N. Landa.
} 
D. Nicolás Buttler. Del comercio local. Con Buena fortuna. Recién viudo. Con una hija de catorce años. Tiene influjo.

D. Juan Pomareda. Casado sin familia. En la familia en cuya casa casó hay muchachas de influjo, todas patriotas. fortuna.

D. Ignacio Marín. Buen patriota y de algún influjo. Casado. Con familia, de mediana

D. Francisco Marín, hijo del anterior. Mozo de influjo. Casado.

D. Enrique del Solar. Recientemente viudo. Con tres hijos menores. Goza de mediana fortuna.

D. Pedro José Belaúnde. Casado. Con familia. De escasa fortuna. De buena representación y disposición, pero algo tímido.

D. Manuel Lavayén. De influjo. De poca fortuna.

D. José Ferrer. Casado sin hijos. Ejerce el comercio de géneros de Castilla. Con mediano influjo. Algo tímido. influjo.

D. Mariano de la Flor. Comerciante de aguardientes. Ha tenido sus quiebras. Es de bastante

D. José Pizarro. Casado. Sin familia. Ejerce el comercio de Castilla y de aguardientes. Posee buena fortuna y algún influjo.

D. Ramón Vásquez. Soltero. Mozo. Comerciante de aguardientes, los que transporta al Alto Perú en mulas propias. Patriota de los buenos, con mediano pasar.

D. Manuel Vásquez. Hermano del anterior. Casado. Padre de un hijo también comerciante con mulas propias. Buen patriota.

D. Manuel, digo don Pedro Antonio Julio Rospigliosi. De buen espíritu, aunque con una pierna menos. De influjo. Muy de a acaballo. Activo. Entusiasta. Casado. Con poca fortuna.

El presbítero don Cayetano Palza. Hacendado en el valle de Sama. Declarado patriota.

El presbítero don Casildo Contreras. Patriotismo de comodidad.

El padre animero. Religioso agustino. De bastante influjo.

D. José Palza. Tiene oficinas propias de salitre en la provincia de Tarapacá. Sobre él podrán informar más largamente el caballero don Ramón Ovalle. Tiene mulas propias, aunque pocas. Tiene un hijo mozo que le ayuda en sus empresas. Es patriota de los muy decididos. Posee conocimientos nada comunes. Goza del mayor influjo en Tacna.

Un José que llaman chuto. De bastante influjo, entre los chacaristas y labradores del valle y aún entre las gentes del pueblo, individuo de bastante partido.

En una palabra en todo Tacna, hombres, mujeres, niños, y aún me avanzo a decir que en lo que producen sus tierras, hay patriotismo firme y entusiasmo más que formal.

No se dejarán de conseguir en su valle más de cien caballos y más de quinientas mulas, sin que hagan notable falta.

\section{Valle de Sama}

Don Juan José Zavala. De bastante influjo y buen clérigo. Hacendado. De algunas proporciones.

D. Ventura Zevallos. Buen patriota. De influjo. Con mediana pasar.

D. José Zevallos. Hermano del anterior. De influjo. Con mediana pasar.

D. Manuel Liendo. Hacendado. Buen patriota. Con influjo. Tiene mulas propias.

Estos tres son los que gobiernan a todo Sama.

Entre estos, por influjo, hay doña Agustina Ortiz, hacendada. Su marido es buen patriota, pero hombre para nada.

El doctor don F. Ureta, cura del valle. Arequipeño buen patriota. 


\section{Valles de Sitana y Locumba}

D. Pedro Vicente Cornejo. Moqueguano. Tiene numerosa familia, toda de mucho patriotismo. Escaso des fortuna. Tiene un solo hijo varón que le ayuda en sus negocios. Su restante familia es de hijas mujeres.

D. Jacinto de Vargas. De influjo grande.

D. Tadeo Rospigliosi, hermano político del anterior. De bastante influjo.

D. Bruno Vargas, hijo de don Jacinto de Vargas. Con alguna comodidad y de bastante influjo.

D. Gregorio Aramburú y Cornejo. Casado. Con familia. Con escasa fortuna.

D. Juan Vértiz. Sujeto de toda confianza y muy patriota. Tan adicto a la patria que su mayor gloria consiste cuando tiene en sus manos algún papel patriota. Llega a tal extremo su afición patriótica, que se aprende de memoria dichos papeles. Un primo suyo don Manuel F. Galdós. Soltero, hombre de mucha habilidad y prestigio. Patriota declarado.

D. Nicolás Vértiz, padre de don Juan Vértiz, vecino de Ilabaya, valle arriba de Locumba. Es capitán retirado y buen patriota.

D. Manuel Cornejo, receptor de alcabalas, declarado patriota aunque un poco truhán (sic).

D. Jacinto de Vargas el Mozo, alocado en materia de patriotismo. en Tacna.

En el pueblo de Ilabaya, donde residen estos vecinos, hay patriotismo mucho, lo mismo que

\section{Villa de Moquegua}

El capitán comandante de las milicias de caballería don Blas Antonio Mendoza. Casado, con bastante familia. Hombre de posibles, sumamente decidido y acérrimo defensor de su amo el rey. Crítico consumado del patriotismo. Fue capitán comandante de Dragones de aquellas milicias, ya retirado del servicio.

D. José Carlos de Mendoza. Es el más pudiente en fincas y dinero efectivo de esta villa. Para él no hay más patria, ni más rey que el trabajo de sus haciendas y el atesorar con lo que ellas rinden. Casado y sin hijos.

Su mujer es una matrona de talento, un poco inclinada al rey.

D. Manuel Rubio. Español. Casado y sin hijos. Comerciante, y de bastante fortuna en géneros y en efectivo. Es el europeo de más malas intenciones que pueda imaginarse, pues ha dicho que mientras no haya un degüello general, no se apaciguarán los pícaros americanos.

D. Tomás Navarro. De igual manera español y del mismo molde que el anterior. Casado, con una hija.

Un andaluz, guarda de la aduana. Es hombre sumamente malo y de ideas perversas. Denunciador de los patriotas. Hombre de malas entrañas. Soltero.

D. Baltasar Dávila, guarda mayor de la aduana. Moqueguano. Casado, con familia, apasionadísimo por el rey. De ninguna fortuna.

El coronel retirado don Fulano de la Flor. Coronel retirado de aquellas milicias. Pudiente y defensor de su amo el rey. Hombre bruto (sic) con visos de racional.

D. José Santiago de la Flor, hijo único del anterior. Apasionado al rey. Fue uno de los que costearon la expedición de cien hombres que se despacharon contra Tacna en ocasión de su segundo levantamiento. Lo mismo que su padre, demasiado bruto (sic).

D. Agustín Zapata, alférez real. Hombre de posibles. Auxiliador de cuanto patriota ha sido perseguido, y aún de muchos patriotas incógnitos, los cuales han recorrido el Perú haciendo propaganda por la patria. Los más de estos han pasado en su casa, por segura. Al despacharlos don Agustín Zapata los ha auxiliado con mozos, cabalgaduras y dinero. A influjos de éste fue mi venida a Lima, de manera que siempre se halla sin dinero por los muchos auxilios que presta en casos de socorrer a patriotas. 
D. Agustín tuvo en su casa durante quince días a los patriotas hechos prisioneros en la acción de Viluma, perdida por el general Rondeau. Los vistió y regaló muy bien. Sin Hijos.

D. Juan Marcos Angulo, fiel ejecutor. Con bastante familia y poca fortuna. Muy patriota.

D. Santiago Zapata, capitán de milicias. Hermano del alférez real don Agustín ya nombrado. Muy patriota, casado con bastante familia, de mediana proporción.

D. Miguel Fajardo. Yerno del anterior. De escasa fortuna. Decidido patriota.

D. Julián Hurtado. Regidor del Cabildo. Casado, con familia, de mediana proporción, patriota.

D. José Angulo, alguacil mayor. Con familia, escaso de fortuna. Decidido patriota.

El doctor don José Egidio de Barrios. Abogado, casado, con una hija, de mediana proporción. Patriota reservado.

D. Julián Montalvo. Joven. Soltero. De mediano conocimiento. Decidido patriota.

D. Luis Mendoza. Con bastante fortuna y mediana suerte. Muy decidido patriota.

D. Francisco Velásquez, contador de la aduana. Casado y sin hijos. Muy patriota. influjo.

D. Juan Villanueva. Oficial mayor de la aduana. Soltero, muy adicto al patriotismo, de influjos.

D. Andrés Cornejo. Primo del anterior. Casado, sin hijos. Comerciante. Patriota, sin

D. Santiago de los Ríos. Casado con familia. Con poca comodidad y algo veleta, pero muy inclinado al patriotismo.

D. Bernardo Ríos. Hijo del anterior, mozo patriota.

Doña Petronila Corrales. Viuda. Con una hija. Persona de comodidad en el comercio de géneros de Castilla que ejerce, de alguna edad, pero acérrima patriota.

Doña Mariquita Yáñez. Soltera. Moza de singular patriotismo, festejada.

D. Francisco Cayetano Alayza. Casado, con familia, de regular fortuna. Hombre de buenos conocimientos, fino, muy civilizado, y patriota decidido. Su esposa doña María Rivero es mujer de buenos talentos. Su apellido dice de su patriotismo, el cual es sin igual en las de su sexo, en esta villa.

Doña Petronila Besoaín. Viuda. Con dos hijos, muy patriota.

D. Pedro Gastón y Besoaín, hijo mayor de la anterior. Hombre de bellos conocimientos y buen patriota. Tiene un modesto pasar.

D. Bernardo Landa y Vizcarra, subdelegado y comandante de milicias. Casado. Con familia, escaso de fortuna. De buena disposición y de espíritu atrevido para cualquier empresa. Muy jinete. Es mi hermano y no puedo decir más de él, dejando que la experiencia denote sus cualidades.

Forman parte de la clerecía los siguientes religiosos:

El doctor don Luis Prieto, vicario.

D. Francisco de la Flor, presbítero.

D. Manuel Vizcarra, presbítero.

D. Mariano F. Salas, presbítero.

El doctor don Narciso Velásquez y Zapata.

El doctor don José María Hurtado.

El presbítero don Hilario Hurtado.

El doctor don Mariano Velarde, cura retirado.

El presbítero don José Tébez.

Todos ellos patriotas.

Religiosos del convento de Santo Domingo: El prior. De los cinco frailes, uno, el padre Sotillo, es realista. Religioso del hospital de nuestra señora de Belén. El prefecto, don José de las Ánimas. Otro del mismo instituto, confinado en él por patriota. Gran poeta, no sé su nombre. 
Franciscanos de Propaganda Discordia, digo de Propaganda Fide. Son catalanes, pero entre ellos hay criollos. Fray José Maldonado. Fray José Zabalaga, Fray José Chávez (este es un santito) los otros tres son americanos y muy patriotas, siendo uno de ellos Fray Buenaventura Solar patriota?

El doctor don Mariano de Ureta, natural de Arequipa, establecido en Locumba y su mujer, moqueguana, ambos patriotas decididos. influjo.

Todos estos nombrados, pertenecientes a la villa de Moquegua, son personas de mucho su familia.

En Arequipa conozco como persona de particular influjo a don Manuel de Rivero y a toda

D. Estanislao Araníbar, yerno del anterior.

D. José Domingo Alvizuri, patriota.

D. José María Alvizuri, hermano del anterior. Adicto al rey.

El doctor don Manuel de Ureta. El presbítero don José Tristán, el cura Iglesias.

D. Narciso de Somocurcio.

Las monjas Catalinas, los religiosos mercedarios, los franciscanos, y los más de los domínicos (Cúneo Vidal, 1921, p. 261).

\section{Bernardo Landa y Miller}

Poniendo en práctica el plan diseñado por San Martín, Miller en mayo de 1821 desembarca en Sama y avanza hacia Tacna. Uno de los voluntarios que se presenta fue Bernardo Landa, que abandona su cargo de subdelegado de Moquegua. Miller en sus memorias lo describe como "de unos cincuenta años; de cinco pies y once pulgadas [1,80 m] de estatura; un tanto delgado, pero de huesos abultados; rostro encendido y despejado y ojos penetrantes". Después de ofrecerle sus servicios le dijo

dirán a usted que he sido en otro tiempo un atroz perseguidor realista, y dirán a usted la verdad [...]. Usted no conoce las localidades de este país, cuando yo, por el contrario, conozco a todo el mundo y sé a palmos todo el terreno en los puertos intermedios [...] le empeño la palabra de un soldado de que jamás tendrá motivos de arrepentirse de la confianza con que tenga usted la bondad de honrarme. (Miller ¿1918?, p. 313)

Con el objeto de combatirlo, el general realista Ramírez ordenó que un destacamento de Arequipa al mando de La Hera saliera en su busca. Otros debían partir desde Puno y Oruro con el propósito de juntarse en Tacna. Enterado Miller del plan, decidió batirlos por separado. Guiado y aconsejado eficazmente por Bernardo Landa, que marchaba liderando la vanguardia a través de los accidentados caminos que conocía a la perfección, con 300 hombres logra dar alcance a La Hera en Mirave, y lo derrota el 22 de mayo de 1821 en una jornada memorable, los vencidos fugan a Moquegua. B. Landa parte en pos de los fugitivos y los alcanza en la salida de Moquegua, aniquilándolos por completo. Al llegar Miller a Moquegua, el 24 de mayo, es recibido con las mayores muestras de entusiasmo. En el informe que envía a Cochrane le dice «no puedo dejar de mencionar enalteciendo a los habitantes de este pueblo, cuyo patriotismo es merecedor del más grande elogio que yo sea capaz de expresar» (Instituto Nacional Sanmartiniano [INSM], 1997, p. 71). El coronel Mariano Portocarrero ${ }^{10}$, subdelegado interino, decide

\footnotetext{
${ }^{9}$ El nombre correcto es Buenaventura Polar.

${ }^{10}$ Nacido en Moquegua, hijo de Ramón Portocarrero y de Francisca Pérez de Tudela Hurtado de Mendoza, quienes se casaron el 30 de marzo de 1778. Pierde a su padre a los dos años de edad. En 1816, es nombrado subdelegado de Tacna y 18 vecinos de Moquegua le otorgan carta fianza, entre ellos Tomás Landa y Agustín Zapata. Fue uno de los agentes secretos de San Martín antes de la invasión patriota. "Portocarrero -escribía Cochrane a San Martín- está poniendo todo en movimiento para levantar el interior” (Mitre, 1951, p. 776). En 1821, San Martín lo asciende a general de brigada y luego es condecorado con la Orden del Sol. En Lima, por decreto del 3 de marzo de 1823 , se crea la "Falange de beneméritos" al mando del general de brigada Mariano Portocarrero, integrada por buen número de moqueguanos y tacneños (Leguía, op. cit. p. 347). Mantuvo correspondencia y fue un cercano colaborador de Bolívar. Testó en 1837.
} 
unirse abiertamente a las huestes patriotas a las que ya venía apoyando desde el anonimato; había mantenido correspondencia con personajes de la talla de Belgrano, San Martín y O'Higgins. Miller, en el citado informe, da cuenta de «el subdelegado Portocarrero, queda tranquilo. De su cooperación e influencia, junto con el gran asesoramiento y tácito apoyo del coronel Landa, quien sobre toda ambición me rindió el más grande servicio de lo que espero mucho» (Miller, ¿1918?, p. 322) (Leguía, 1972, p. 107) (Cf. Otero, 1944, p. 270).

Al día siguiente, Miller se entera que 150 españoles, que habían salido de Puno y que no pudieron unirse a La Hera, pasaban por las alturas de Torata. Les da alcance y los derrota en el punto denominado La Calera, a 14 leguas al este de Moquegua. Para ello, contaba con refuerzos de caballería que Bernardo Landa había conseguido en la villa de Moquegua. Cuando se aprestaba a continuar con su exitosa lucha, recibe la noticia del armisticio de Punchauca y decide replegarse a Tacna. Al finalizar la tregua, es advertido que parten tras él fuerzas superiores que salieron de Arequipa, entonces decide embarcarse rumbo al norte. Lo acompañan, entre otros, B. Landa, M. Portocarrero, Agustín Zapata ${ }^{11}$. El 5 de junio se unen al ejército libertador unos jóvenes entre ellos Domingo Nieto (INSM id., p. 77; Ruíz 1942, p. 141).

El general e historiador García Camba (1916), que tomó parte en estas luchas como integrante del ejército realista, señala al influyente teniente coronel Bernardo Landa como una de las figuras más sobresalientes de esta victoriosa campaña patriota. En sus citadas memorias dice de Landa:

engreído Miller con las ventajas obtenidas a tan poca costa, y aumentada su fuerza moral y física, se estimó capaz de acometer mayores empresas, confiado también en la cooperación de los partidarios que se le iban descubriendo en los pueblos y en las relaciones y conocimientos prácticos del teniente coronel Landa, subdelegado que había sido del partido de Moquegua. (p. 531)

En una carta que Miller escribe a San Martín desde Moquegua el 23 de mayo de 1821, después de las acciones de Mirave, le dice "[...] con el gran asesoramiento y tácito apoyo del coronel Landa, quien sobre toda ambición me rindió el más grande servicio de lo que espero mucho [...]” (INSM, 1977, p. 276) (Odriozola, 1873, p. 276). Años después, refiere en sus memorias que Bernardo Landa es de aquellos "cuyos nombres no se han citado especialmente, y reclama con justicia la historia". Por su parte, el historiador Bartolomé Mitre (1952, p. 776) dice que "Landa fue el hombre de la expedición, sin él habría fracasado desde el principio, y Miller no hubiera obtenido las señaladas ventajas que alcanzó". Cochrane también se refiere a él en términos elogiosos.

El historiador M. Nemesio Vargas (1903, p. 187) califica que

su cooperación resultó eficaz, por ser muy práctico en los caminos. Con él no había temor de extraviarse en la costa o en la sierra de día o de noche; no dejaba escapar la menor oportunidad para atacar con ventaja al enemigo; y a una vista de lince reunía un aplomo y serenidad a toda prueba.

¿Participó Tomás Landa en esta campaña en la que destacó nítidamente su hermano Bernardo? En una carta que Miller le escribe a San Martín le recomienda por su buen comportamiento a los capitanes José Videla y José María Plaza, del graduado don Vicente Suárez, del subalterno Guillermo de Hill y del ayudante Estanilado Correa, como del teniente graduado de capitán Juan Valdés. Agrega "Los señores capitanes del ejército don Tomás Landa, don Lorenzo Balderramo (sic) y don Pedro Gil han hecho lo que ellos han podido", citado por Otero (1944, p. 27).

\footnotetext{
${ }^{11}$ Eguiguren (1961, p. VII) dice que "los patriotas de Moquegua estaban representados por el alférez real don Agustín Zapata y su hermano
} don Santiago, capitán de milicias". 


\section{Los hermanos Landa en Lima}

Los hermanos Landa, una vez refugiados en Lima, viven en una casa destinada por el gobierno para los emigrados de Tacna, Sama y Moquegua. Como era de esperarse, estando alejados de sus hogares y haciendas su situación no era de las mejores. El 1 de octubre de 1821 Bernardo le dirige una carta al Protector San Martín. En ella le da a conocer que "el 23 del pasado agosto puse en manos de V. E. un memorial acompañado de varios oficios y cartas que acreditaban en parte los servicios que tengo hechos a la tan justa causa que defendemos" con lo que buscaba justificar la ayuda que solicita, bien a través de un préstamo hasta cuando saliere la expedición para "aquellos puntos de mi domicilio y nacimiento" donde le asegura que podrá devolverlo; o bien -pide- se le confíe la administración de una hacienda estatal, pues su situación era tan apremiante que para su sustento se vio obligado a vender sus prendas personales "[...] dos uniformes, una capa, una levita, seis pantalones, unas hebillas de oro, y el reloj, pues de otro modo no hubiese podido subsistir en esta ciudad [...]". Situación tan desafortunada que se hace crítica cuando el presidente Riva Agüero les pide que desalojen la casa que les fuera facilitada por orden de San Martín (AGN, O.L. 20 - 40). El pedido es pronto atendido, un mes después recibe 250 pesos y montos diversos por vías de auxilio en meses posteriores.

En mérito a su activa participación en pro de la campaña emancipadora, en 1821 el sargento mayor graduado de caballería capitán Tomás Landa es condecorado con la Orden del Sol en la clase de Asociado, haciéndose merecedor a una pensión anual de 200 pesos. Otro moqueguano que por sus meritorios servicios a la patria recibió esta Orden fue el general de división Mariano Portocarrero. Esta Orden fue fundada el 8 de octubre de 1821 y constaba de tres clases, la de "Fundadores", "Beneméritos" y el de "Asociados". Paralela a la del Sol, se crea una Orden femenina, por decreto del 11 de enero de 1822, para premiar a "las patriotas que más se hayan distinguido por su adhesión a la causa de la independencia del Perú”, una de las agraciadas fue la moqueguana Bárbara Alcázar (Suplemento a la Gaceta del Gobierno de Lima Independiente, 1822, Nº 5, (p. 290), No 11 (p. 583) y No 45 (p. 241); Leguía (1972)).

Para entonces la campaña al sur ya estaba en preparación. Para tal efecto, los hermanos Landa reciben 600 pesos el 28 de junio "por vía de auxilio para gastos de guerra". Y es así como el bergantín Belgrano y la goleta Cruz parten para Ilo donde, con otros compañeros, desembarca Bernardo Landa para luego dirigirse a Moquegua, su final destino, a donde llega los primeros días de julio.

\section{El fusilamiento de Bernardo Landa}

El día 10 las autoridades ya tenían conocimiento de los encuentros de Bernardo con sus allegados en la villa y de sus correrías por el valle desde días atrás. Esa misma noche se hace presente en el pueblo y visita audazmente al subdelegado Tadeo Ordóñez con quien sostiene una entrevista. Este informa a sus superiores que Landa había desembarcado por Ilo "[...] su visita y arrojo me tiene sorprendido [...] solo venía en busca de algún auxilio y que se volvía al momento a embarcar en la costa [...]. Su paradero debe ser de día en el valle y la noche en la villa [...]" (BNP, D 4728). Al día siguiente, Ordóñez busca al comandante militar Anselmo Gago y lo pone al tanto de este encuentro. Juntos inician la persecución de Landa, y Gago no tarda en hacer de conocimiento de estos sucesos al brigadier José Santos de la Hera, que se encontraba en Arequipa.

El día 13 la Hera, muy indignado, recrimina acremente la "debilidad criminal" del subdelegado Ordóñez por no arrestar "al traidor Landa", cuando pudo haberlo hecho con el personal de servicio, y le encara que solo puede vindicar su honor capturándolo vivo o muerto, a la vez que oficia a Gago autorizándolo a fusilar al rebelde a las dos horas de su captura, "tomándole antes una exacta declaración de todo lo que pudiera ilustrarnos sobre el estado y proyectos del enemigo". Por la importancia que significaba la presencia de quien se consideraba era un líder revolucionario, se ordena redoblar el patrullaje y se extreman las medidas de vigilancia, tanto en la población como en el valle (BNP, D 4728). 
Una semana después, Gago informa a la Hera que la noche anterior Landa "fue preso herido [...] y pagó sus crímenes a las 9 de la mañana de este día pasándolo por las armas por detrás como a traidor". Bernardo Landa fue fusilado en la pampichuela del Huayco y sepultado en este lugar en anónima tumba, por cruel ironía cerca de las tierras eriazas al borde del camino a Samegua, que había comprado "en el pago del Guayco" de Elena Zapata en 1816 cuando era subdelegado (Archivo Regional de Moquegua [ARM], P. A. del Alcázar 1816, f. 339v. Era el 20 de julio de 1822).

El mismo día del fusilamiento, La Hera escribe al virrey la Serna que se encontraba en el Cusco. Le envía el informe de Anselmo Gago en el que cuenta: "Anoche como a las 7 sorprendí con tropa armada la casa de don Felipe Vélez, en donde se decía que se hallaba el caudillo Landa [...] fue preso herido y conducido al cuartel en donde después de tomada su confesión [...] pagó sus crímenes por detrás como a traidor [...]". Dos días después, La Hera le comunica al virrey que adjunta "[...] los papeles que se encontraron en poder del rebelde, excepto dos cartas anónimas con las cuales me quedo por ahora". Fue fusilado a las 9 de la mañana. La noticia fue publicada en la Gaceta del Gobierno Legítimo del Perú, Cuzco $1^{\circ}$ de agosto de 1822 . El 31 de julio el virrey dispone que al negligente doctor don Tadeo Ordóñez se le abra juicio sumario y le envíe preso a la ciudad de Arequipa por no haber capturado al rebelde, amenazando

y a todos los demás que pudieran resultar complicados en ella serán juzgados militarmente en consejo de guerra ordinario [...] en la confesión tomada a Landa se omitió haberle preguntado si estuvo en la casa del subdelegado Ordóñez y si habló con él [...] Preso y muerto Landa creo aminoramos los cuidados que con su existencia en Moquegua ofrecía a aquel Partido [...]. (BNP, D 4728)

La satisfacción era evidente ${ }^{12}$.

El 12 de agosto Anselmo Gago, después de haber cobrado 200 pesos como recompensa que ofreció José Santos de la Hera "[...] por premio a los que tuviesen la suerte de presentar vivo o muerto al traidor Landa [...]", se hace cargo de la subdelegación de Moquegua ${ }^{13}$. Pero pronto es relevado de su cargo por La Hera quien recibe el encargo del virrey; fue reemplazado por el capitán del batallón Gerona Julián la Carta “[...] respecto a que el comandante militar de Moquegua teniente coronel don Anselmo Gago no es tan a propósito para el caso como lo prueba la ineficiencia de los medios que puede haber empleado para descubrir a los cómplices del caudillo [Bernardo Landa] [... ]" (BNP, D 4728).

En la persecución que se hizo contra los que ayudaron a B. Landa se apresó a Eusebio Pomareda, que fue liberado luego que el escribano Apolinar Zegarra saliera como su fiador; a Felipe Vélez se le arrestó por haber sido quien lo ocultó en varias ocasiones, y uno de sus fiadores, entre otros, fue Bartolomé Nieto, hermano mayor de Domingo que el año anterior se había alistado al ejercito de Miller (ARM, Apolinar Zegarra, 1822 f. 280; Pedro Antonio del Alcázar, 1822 f. 118).

En la escasa y poco difundida información sobre Bernardo Landa, siempre se consideró que había sido fusilado después de la batalla de Moquegua, el 21 de enero de 1823. Contribuía al equívoco la afirmación que hacía Guillermo Miller (1918) en sus Memorias, publicadas por su hermano John en 1829. Allí nos dice con manifiesto error que "[...] el coronel [Bernardo] Landa, hecho prisionero después de la batalla de Moquegua [fue] fusilado por los realistas [...]”. Aunque el general inglés no participó en la desgraciada expedición de Torata y Moquegua, pues semanas antes fue enviado a Arequipa, la distracción no deja de llamar la atención por haber sido Bernardo Landa su brazo derecho en la exitosa campaña de Mirave. Esta es la primera noticia publicada que se tiene del ajusticiamiento, y la probable fuente para todos los que se ocuparon del tema posteriormente.

\footnotetext{
${ }^{12}$ La copia de los diarios cusqueños en los que se informa de este fusilamiento nos fueron donados con la más amplia generosidad por Horacio Villanueva Urteaga el año 1999.

${ }^{13}$ El 1 de julio de 1824 un total de 34 vecinos de la villa de Moquegua salen como sus fiadores por un monto total de 22,500 pesos. Pero, al separarse de la jurisdicción de Moquegua los pueblos de Pocsi, Mollebaya, Quequeña y Yarabamba para agregarlos al cercado de Arequipa, se reduce el monto de la fianza a 22,500 pesos (ARM, Apolinar Zegarra, 1824 f. 117).
} 
Bartolomé Mitre (1890, p. 14) contribuye a fomentar el error cuando en una nota a pie de página, en su biografía de San Martín, indica que este "[...] tenía como corresponsal un peruano conocedor del país, llamado Bernardo Landa del mismo apellido del famoso baqueano de Miller [...] quien le decía en carta de 22 de diciembre de 1822: no juzgué encontrar tantos auxilios como se han hallado en este punto [...]". Mitre pone como autor de esta carta a Bernardo Landa. Equivocación que difunde el general EP Felipe de la Barra (1974) al citarlo en su libro "La campaña de Juniny Ayacucho" en la pág. 47, Lima.

El error se aclara cuando se publica la carta completa en 1910, y se ve que el autor fue Tomás Landa, quien le dirigió a San Martín unas cartas posteriores más, dándole cuenta de estos sucesos (Comisión Nacional del Centenario [CNC], 1910, p. 136). A todo esto se suma los documentos que encontramos tanto en el archivo local como los periódicos de la época en el Cusco que hemos comentado ${ }^{14}$.

\section{Las batallas de Torata y Moquegua: 1823}

En setiembre de 1822 se retira San Martín del Perú y asume la presidencia José de la Riva Agüero. Para evitar la llegada de Bolívar, decide llevar a cabo la campaña por los puertos intermedios (se llamaban así a los puertos menores que se encontraban entre Callao y Valparaíso) y la encomienda al siempre indeciso general Rudecindo Alvarado. Este se embarcó rumbo al Sur, llega a Arica y luego de permanecer indolentemente inactivo varias semanas, es hábilmente atraído por el brillante estratega español Jerónimo Valdés a las alturas de Torata, donde el 19 de enero de 1823 es derrotado, derrota que se convirtió en desastre el 21 en Moquegua ${ }^{15}$. Después del descalabro, la ciudad fue bárbaramente saqueada por la tropa realista, como escarmiento a un pueblo que venía apoyando de manera espontánea y con decisión las luchas por la independencia.

Tomás Landa participó en esta expedición, convertido en el corresponsal de San Martín. Le escribe una carta inicial el 22 de diciembre de 1822, le da cuenta de la partida del ejército al sur y lo bien que fueron recibidos en Arica (un párrafo de esta carta es reproducida por Mitre e inadvertidamente se la atribuye a Bernardo Landa, como ya se analizó). En la carta que le escribe una semana después, el día 30, sin moverse de Arica, le cuenta que unos paisanos con "algunos indios y sin más armas que palos y piedras prendieron a cinco soldados europeos de Gerona y a un oficial, el mismo que desnudó a mi hermano cuando tuvo la infelicidad de caer en sus manos"; y le da cuenta del avance del ejército rumbo a Tacna.

En otra, fechada en Lima el 23 de febrero, le hace saber del "fatal e inesperado contraste que ha sufrido el desagraciado y benigno general en jefe, don Rudecindo Alvarado, el 21 del pasado enero, en las cercanías de Moquegua, sepulcro de las vencedoras armas de la patria". Narra la persecución a Valdés hasta las alturas de Torata; lo pone al tanto de los insólitos problemas que durante esta campaña se presentaron en el ejército, en el que "reinaba la inobediencia, la etiqueta, y lo que es más la disensión entre los jefes". Cuando ingresaron a Moquegua ofrece su dolido testimonio "[...] del destrozo de aquellas haciendas: rotas sus bodegas y vasijas de vino y aguardiente, saqueadas las casas en tal extremo, que ni las camas de criados y mayordomos dejaron, pero aún la de los dueños, rompiendo cajas y baúles, como si hubiesen entrado a un país de enemigos los más tenaces [...]". Al llegar a Torata, indica que la mayor parte de lucha la padeció la legión peruana. Al ser derrotados y teniendo a un enemigo reforzado con Canterac, retrocedieron a Moquegua donde el 21, luego de dos horas de combate, se quedaron sin municiones, y empezó la desbandada, perdiéndose todo al fugar desesperadamente hasta Ilo. Y concluye diciéndole que "su viejo cojo solo pudo escapar tan sólo con la ropa del cuerpo".

\footnotetext{
${ }^{14}$ La dirección Regional de Cultura de Moquegua emitió una resolución de reconocimiento el 21 de enero del 2012 en la que confunde a los hermanos Tomás y Bernardo Landa, y asume como fecha del fusilamiento la errónea de 1823.

${ }^{15}$ Cinco meses después Riva Agüero repetiría la operación al mando de Santa Cruz, en el mismo escenario y con los mismos funestos resultados, precipitando su caída y con ella la llegada de Bolívar al Perú. Por su heroísmo en las campañas a Intermedios la ciudad de Moquegua fue declarada en 1828 "benemérita a la patria" y el pueblo de Torata elevado a la categoría de villa.
} 
Luego del desastre retorna a Lima, donde continuó viviendo en medio de la mayor penuria, agravada con la crisis que pasaba el naciente gobierno hasta el extremo de no poder atender las necesidades de los combatientes ${ }^{16}$.

Mientras se encontraba refugiado en Lima, su sobrino el regidor José Clemente Arguedas presenta en la villa de Moquegua una carta fianza con la idea de favorecer a su tío. En ella indicaba

que por orden del señor comandante general, se ha mandado hayan de reunirse todos los oficiales que por haber servido en las tropas de la patria, se han presentado a gozar del indulto que se les concedió por el excelentísimo señor virrey, para que sigan la marcha con el ejército acantonado en el pueblo de Torata; y habiendo quedado don Tomás Landa mi tío, exceptuado de esta obligación, según lo previene el señor comandante accidental don [en blanco] Polo, en un oficio que al efecto ha pasado con calidad de dar para su seguridad fianza de seis mil pesos para hacerlos efectivos, siempre que hubiere en algún tiempo de aparecerse por estos lugares tropas de la patria y no emigrare, he determinado el otorgar esta escritura de fiador por dicha cantidad en favor del citado mi tío, y por la que me obligo a que si llegase a verse desgraciadamente por este lugar dichas tropas, ha de hacer el susodicho forzosamente su emigración a que queda obligado y llano a hacer pudiendo, y no tenga impedimento alguno, y lo que verificará en tal caso al momento de que tales tropas sean vistas, bajo de la calidad de que no lo haciendo quedo ligado necesariamente a la responsabilidad de los seis mil pesos con que lo aseguro por esta escritura, y expresa obligación de mis bienes a su seguridad, y con sumisión a las justicias y jueces [...] firmado en la villa de Moquegua en 23 de febrero de 1824. (ARM, Apolinar Zegarra, 1824 f. 41)

Por su persistente trayectoria patriota, en 1825 Tomás Landa fue distinguido nuevamente, en esta ocasión con la medalla de plata ${ }^{17}$.

\section{Un valioso documento inédito}

Tomás Landa, como protagonista y testigo de excepción de las luchas libradas contra las fuerzas realistas en suelo moqueguano, conocía a quienes habían apoyado al ejército libertador cuando pasó por este valle, y a quienes a costa de su vida se arriesgaron después de la derrota a socorrer a los heridos y ayudar a escapar a los que emprendían la desesperada retirada. Meses después, cuando se hacen los reconocimientos oficiales correspondientes, se favorecieron a quienes no lo merecían. Entonces levanta su voz de protesta, y hace patente su reclamo a través de un memorial, en el que rescata del olvido a sus sacrificados y valerosos paisanos a quienes consideraba se debía un homenaje y guardar la gratitud nacional por su sacrificio puesto de manifiesto en estas campañas, que en algunos casos los llevó a la ejemplar inmolación.

En enero de 1826 envía al Supremo Gobierno el Informe y pide que sea puesto a consideración del Libertador Simón Bolívar. Reclama que se reconozcan los méritos de varios vecinos de Moquegua. Este es un valioso documento de gran trascendencia para la historia local, que aquí por primera vez se publica en su integridad, en la que actualizamos la ortografía de los apellidos, para que se haga efectiva la justicia correspondiente con la memoria de los nombrados.

\footnotetext{
${ }^{16}$ Ramón Herrera, a nombre del teniente coronel Tomás Landa, reclama el 1 de mayo de 1823 se le pague los haberes que le adeudan (AGN, O.L. 71-75).

${ }^{17}$ En el periódico de Arequipa "Estrella de Ayacucho", No 27 del 3 de agosto de 1825, se informaba que, entre otros, se había calificado el expediente del coronel Tomás Landa, a quien se había galardonado con el premio condigno.
} 


\section{INFORME SOBRE LOS SERVICIOS DE ALGUNOS VECINOS DE MOQUEGUA PARA QUE SE LES DÉ MEDALLAS}

El patriotismo que decora a muchos honrados vecinos de esta ciudad, y que con sacrificios notorios de sus intereses han servido esforzadamente a la causa pública de nuestra independencia, distinguiéndose muy particularmente en los aciagos y fatales contrastes que sufrieron las armas de la patria el 21 de enero y el tantos de setiembre del año 1823, parece que justamente son merecedores del premio que sabe repartir la patria a sus buenos y constantes servidores. Entre los muchos adictos que hubo y hay en esta ciudad, los más recomendables a la consideración del Gobierno Supremo por haberse distinguido en servicios poco practicados, exponiendo sus vidas al sacrificio que de continuamente perpetuaban las manos sangrientas del tirano español por el odio implacable que tenían al hombre americano, son los siguientes:

Don Valentín Pomareda, no solamente sirvió con su persona, y avisos e industria, sino que también con su dinero y cabalgaduras, ocultando oficiales y haciéndolos conducir, y las más veces acompañándolos como práctico por extraviados caminos hasta ponerlos en salvo, proporcionándoles buques en que fuesen embarcados, cuya operación hacía abandonando su familia y otros intereses por favorecerlos, \&.

Don Juan Marcelino Puertas, tuvo que fabricar un sótano en su casa, sin más ayuda que la de su esposa doña Rita Dávila, a fin de no tener testigos para ocultar en él oficiales, sin temor de los alojados enemigos que le pusieron, y a unos y otros mantuvo sin ser descubierto hasta lograr remitirlos a la costa para que se embarcasen.

Don José Clemente Arguedas, este individuo solo pudo manifestar su adhesión auxiliando reservadamente a todo disperso con dinero y ropa.

Don Francisco Valcárcel y Zapata, en fuerza de su entusiasmado patriotismo, sin reparar el riesgo evidente a que se expuso por hallarse el G. Valdés acantonado al lado de arriba de esta ciudad y sus partidas volantes cruzando el valle abajo; luego que este individuo se impuso haber llegado el S. G. Alvarado con toda su división al lugar de La Rinconada, cinco leguas debajo de esta ciudad, con poca cautela e impulsado de su ardimiento patriótico, se puso a pedir bestias por las haciendas, de las que estaban ocultas para llevarlas en auxilio a los de la patria; mas por su ninguna precaución fue descubierto y conducido a la presencia de Valdés, el que en el acto mandó se le fusilase, de cuya fatalidad se libró por la súplica de los eclesiásticos, algunos particulares y muchas mujeres que le importunaron, y como también se acercaron con prisa los escuadrones de la caballería, tuvo el inhumano que retirarse a Torata abandonando al sentenciado.

El presbítero don Ilario Hurtado, salvó de las manos del obispo Encina el año 1814 al desagraciado y digno de mejor suerte doctor Muñecas, y juntamente a sus compañeros, ocultándolos con seguridad en casa de una patriota pobre, en donde los mantuvo todo el tiempo que fue necesario para diligenciar bestias y mozo de confianza que los sacase para Locumba y al Alto Perú, todo lo que hizo a sus expensas, y otros servicios particulares que practicó después siempre con el mismo entusiasmo.

Don Esteban Pérez, en servicio de la patria perdió su buque, única hacienda que poseía para subsistir. Servía en el mar impartiendo noticias de las posiciones y disposiciones del enemigo a los transportes de nuestras expediciones, y aún a la escuadra. Habilitando con dinero y vestuario a todo disperso que tocaba al punto de Ilo, y en su embarcación condujo a muchos en traje de peones, hasta dejarlos en salvamento, \&.

Don Ignacio Pomareda, ha servido ocultando soldados en los montes de su hacienda, en donde los socorría con lo necesario, y mantuvo cinco en calidad de peones sirvientes, a los que mantuvo defendiéndolos de la persecución infatigable con que los solicitaba el enemigo, desde la dispersión del G. Santa Cruz hasta el felicísimo día 9 de diciembre, en que libres como todos 
marcharon a sus tierras, no pudiendo en el año de 824 descubrirle uno, no obstante haberle acusado, por cuya causa le condujeron preso y a pie hasta Torata, en donde se le amenazó con la muerte.

Don Miguel Fajardo, sumamente patriota, y como vivía en el pasaje para Ilo, auxilió con víveres a cuantos por allí tomaron la dirección de aquel punto en el contraste del G. Alvarado.

Doña María Galdos y Yáñez, fundadora del patriotismo en este lugar, pues desde los primeros momentos en que se posesionó Castelli del Alto Perú, descubrió su opinión públicamente manifestándose defensora de la justa causa y fue la que desplegó sin temor su entusiasmo con auxiliar a los que remitió prisioneros Goyeneche por esta vía para Lima, \&.

Doña Jacinta Dávila y Flor, del mismo modo se manifestó auxiliando a los heridos del 21 de enero y a muchos otros que haciéndoles fingir heridas con la capa de curarlos, los tuvo en su casa socorriéndolos de todo lo necesario, hasta que un poco descuidado el enemigo les proporcionó la fuga, facilitándoles bestias y mozos de confianza que los condujesen, todo a expensas de su peculio.

Doña Emilia Casanova, en medio de sus escases, sacó del hospital con fianza de cinco mil pesos a un oficial herido, al que llevó a su casa costeándole médico, medicinas, y mantención el espacio de dos meses, teniendo la desgracia de morírsele, y así le hizo enterrar con pompa; en aquellos ratos que le proporcionaba la asistencia previa del enfermo, corría al hospital llevando limosnas para el hospital a los soldados enfermos, y últimamente dio su mula última que tenía para sus diligencias, para conducir a la costa a un artillero de los de Chile que buscaban con empeño los enemigos, y se les había escapado de la prisión engañándoles con que tomaba partido con ellos.

Doña Martina Nieto y Tapia, sin temor de dejar a sus tiernos hijos en la indispensable mendicidad, corrió a los hospitales a sacar heridos, afianzando con cinco mil pesos, no teniendo más bienes que su corta casa, y su trabajo personal. Para medicinar las heridas de aquellos, destrozó la poca ropa que le dejaron para hilachas, y las alhajitas que pudo escapar de aquellos días terribles de saqueo, las vendía para medicinas y mantención de los infelices heridos.

Sería cansar demasiado la interesante atención de V. S. si me pusiera a hacer relación de los servicios y padecimientos de los patriotas de este mi país, es notorio y bastante público el estado de miseria a que los redujo la barbarie de los tiranos españoles; solo me contento con hacer presente a V.S. [los] de mayor mérito por su constancia, por sus hechos positivos, y por su desinterés personal en favor de la causa pública.

No se me juzgue por pasionista en el particular, ni me arrastra algún interés particular, lejos de mí semejante pensamiento, sólo me impele a ello la ambición que me domina al bien general de toda la América. He trabajado y padecido por el bien justo de nuestra emancipación, ya la he visto jurando nuestra independencia, sólo me atormenta el dolor de ver condecorados con la honorífica gracia que ha dictado el gobierno en favor de los buenos servidores de la patria, concediéndoseles el distinguirse con la medalla en que se halla grabado nuestro amabilísimo Libertador, el Grande Macabeo Americano S. E. Simón Bolívar, y que esta se ha concedido a personas que si han sido patriotas lo han manifestado en los rincones más ocultos de sus casas, y que eran patriotas con las tropas de la patria y realistas con las del rey. Yo suplico a V. S. interesando los respetos de V. S. y su verdadero entusiasmo por la causa, a favor de los verdaderos patriotas, los que veo con desaliento al verse entregados al olvido por no tener valedores a causa de ser pobres, y los que no han sido sino egoístas, huérfanos y llenos de honor, de suerte que la feliz campaña de Ayacucho les fue favorable para estos, y contraria para los que infatigables sufrieron desaires, persecuciones, y demás padecimientos consiguientes.

Concluyo suplicando, se digne V. S. con su acostumbrado celo por la independencia, atender a los verdaderos ciudadanos que supieron practicar sacrificios por ver logrado el feliz resultado que gozamos. A V. S. sorprendieron con los nominados para condecorarlos con la honorífica medalla, pues la cargan ufanos contra todo derecho los más de ellos, y solo cuatro o cinco se hallan bien asignadas. Si es el agrado de V. S. elevar a S. E. el Libertador esta mi tan 
desinteresada relación, sería de mi mayor complacencia y vanagloria al considerar que la prensa declaraba a todo un respetable y soberano público el interés de que sea atendido el verdadero mérito como lo recomienda en sus sabios decretos S. E. Libertador.

Tenga V. S. la bondad de saber dispensar al que para ser molesto le impele el fuego de su entusiasmado patriotismo, y queda entregado a obedecer las determinaciones de V.S.

Moquegua 8 de enero de 1826

S...G...P...

Tomás de Landa (firmado)

\section{Fin de una etapa}

Lograda la independencia, luego de una corta residencia en la ciudad de Arequipa, en enero de 1826 el "coronel de ejército" Tomás Landa fue nombrado administrador de la aduana del tesoro público de esta ciudad, ocasión en la que quince vecinos de la ciudad y hacendados en el valle de Moquegua, se ofrecen como sus fiadores por ocho mil pesos. Días después, el 16 de enero, da poder al presbítero Miguel Iramátegui, vecino de Lima, para que se presente “[...] ante el soberano Congreso y Senado y ante cualquier otro tribunal superior que fuere necesario, pidiendo y suplicando se le conceda la gracia, merced título que por asenso le sea correspondiente, mediante los servicios heroicos que tiene hechos a la causa justa de nuestra Independencia [...]", petición que sostiene la podrá acreditar con los papeles, hojas, planes y méritos que ha alcanzado con sus servicios, con lo que busca la confirmación del empleo que viene ejerciendo o de lo que le fuere conferido luego. Poco después fue trasladado a Ilo donde ejerció el cargo de administrador de la aduana litoral del puerto de Ilo (ARM, A polinar Zegarra, 1826 f. 1 y 9).

Testó el 14 de abril de 1831, falleciendo días más tarde sin dejar descendencia.

Inmediatamente después de la campaña de Moquegua, el gobernador subdelegado Anselmo Gago siguió autos ejecutivos contra los bienes del finado capitán Bernardo Landa, por la crecida cantidad de pesos en que vino a salir en descubierto en favor del Estado, "por todos los ramos que corrieron a su cargo en el tiempo que sirvió la sub delegación de esta ciudad cuando regía por villa", como lo acreditaba el informe hecho por el administrador de la aduana, que sirvió para iniciar la acción judicial.

El remate se hizo efectivo en la Plaza Pública el 20 de julio de 1824, coincidentemente el día en el que se cumplía el segundo aniversario de su ejecución, cancelándose la mitad en efectivo y el resto luego de seis meses. Descubrimiento y remate que se hicieron cuando Moquegua seguía bajo la ocupación de las fuerzas realistas y bajo la misma administración que dispuso su fusilamiento.

Fueron asesores de esta causa el reputado abogado Dr. Mariano Esteban de la Llosa -al año siguiente sería vocal fundador de la Corte Superior de Arequipa-; y el defensor de la real hacienda el Dr. José Egidio Barrios, conocido por sus discretas simpatías patriotas (ARM, P. A. del Alcázar, 1827, f. 56).

Como el monto de lo recaudado no alcanzó a cubrir la deuda, se notificó a los que fueron fiadores de Bernardo Landa cuando se le nombró subdelegado, "para que sean reconvenidos al pago solidario por no alcanzar los bienes ejecutivos al lleno del descubierto", a favor del fisco.

¿Cuáles fueron las verdaderas razones para hacer esta acusación tan deshonrosa? ¿Tomó Landa dinero de las arcas reales para apoyar la causa patriota? ¿Lo hizo para su provecho personal? ¿Se trató de una vil venganza?

Se desconoce la naturaleza exacta de esta deuda que se inicia con un pequeño legajo que hemos consultado en el archivo de Moquegua. De su lectura se desprende que los detalles y precisiones se dan en el juicio de cobranza que originó un voluminoso expediente de no menos de dos centenares de folios que, después de haberlo buscado en los archivos de Moquegua, Arequipa y Cusco, hasta hoy nos resulta esquivo.

Las formalidades procesales de la subasta continuaron hasta iniciada ya la República. En 1829 a la viuda del doctor Pedro León de Tapia y Montalvo, uno de los que salió como fiador de Landa, se le embarga un cuarto de vivienda que le servía para sustentar a sus hijos; en 1833 los hijos del fiador Lorenzo Pomareda 
Vizcarra (que en la carta fianza figura como Lorenzo Vizcarra) cancelan los 500 pesos, a los que se comprometió su padre, a favor de las rentas del Estado (ARM, P. A. del Alcázar, 1829, f. 49)

Tal vez la respuesta a estas interrogantes se encuentre en la norma oficial que se aprobó en 1839 a favor de la viuda de Bernardo Landa. Como un gesto de reconocimiento recibió una cédula de montepío librada por el Supremo Gobierno, en apoyo a su atribulada viudez y en auxilio de sus tres menores hijos.

\section{REFERENCIAS}

Archivo General de Indias [AGI]

Archivo General de la Nación [AGN]

Archivo Regional de Moquegua [ARM]

Biblioteca Nacional del Perú [BNP]

Castro, L. (2018). El proceso independentista en el extremo sur del Perú: desde la invasión de Julián Peñaranda a la sublevación de Pascual Flores (Tarapacá, 1815-1822). HISTORIA, II (51), 365-392.

Comisión Nacional del Centenario. (1910). Documentos del Archivo de San Martín. Buenos Aires: Coni hermanos.

Cúneo Vidal, R. (1921). Historia de las insurrecciones de Tacna. Lima: Imprenta Gil.

De la Barra, F. (1974). La campaña de Junín y Ayacucho. Lima: Comisión Nacional del Sesquicentenario de la Independencia del Perú.

Eguiguren, L. (1961). Hojaspara la historia de la emancipación delPerú. Lima. s/e.

Gálvez, A. (1909). El RealFelipe, segunda parte. Lima: imp. Liberal.

García, A. (1916). Memorias. Madrid: edit. América.

Herrera, J. (1862). Elálbum de Ayacucho. Lima: tipografía de Aurelio Alfaro.

Instituto Nacional Sanmartiniano [INSM]. (1997). Documentos para la historia del Libertadorgeneral San Martin. Buenos Aires.

Leguía, G. (1972). Historia de la Emancipación del Perú: ElProtectorado, 7 vol. Lima: Edit. Jurídica S.A., colección documental de la Independencia del Perú.

Lilly Library Indiana University, Latin American Mss, Peru, Manuscripts Department.

Mendiburu, M. de (1935), Diccionario bistórico-biográfico del Perú, con adiciones y notas por Evaristo San Cristóval. Lima: librería e imprenta Gil.

Miller, J. (¿1918?). Memorias del general Miller. Madrid: Ed. América.

Mitre, B. (1890). Historia de San Martíny de la Emancipación Americana. Buenos Aires: Ed. Félix Lajoune.

Odriozola, M. de. (1873). Documentos históricos delPerú. Lima: Imp. del Estado.

Otero, J. (1944). Historia del libertador don Joséde San Martin. Buenos Aires, Argentina: Círculo Militar.

Paz-Soldán, M. (1956). Bernardo Landa, en Repertorio de noticias breves sobre personajes peruanos..., selección y recopilación de Alfredo Moreno Mendiguren. Madrid:Ed. s/d.

Pezuela, J. de la. (2011). Compendio de los sucesos ocurridos en el Ejército del Perú y sus provincias (1813-1816). Santiago de Chile, edición y estudios introductorios de Pablo Ortemberg y Natalia Sobrevilla Perea. Ed. Centro de Estudios Bicentenario. Memoria de gobierno, 1816 - 1821, (1947), Sevilla, edición y prólogo de Vicente Rodríguez Casado y Guillermo Lohmann Villena, publicaciones de la Escuela de Estudios Hispanoamericanos de Sevilla.

Ruíz, P. (1942). Apuntes históricos sobre la vida del gran mariscal don Domingo Nieto. Lima: imprenta Torres Aguirre.

Senado Argentino [SA]. (1960). Biblioteca de Mayo.

Suplemento a la Gaceta del Gobierno de Lima Independiente. (1822). № 5. Gobierno Legítimo del Perú, Cuzco.

Suplemento a la Gaceta del Gobierno de Lima Independiente. (1822). No 11. Gobierno Legítimo del Perú, Cuzco. 
Suplemento a la Gaceta del Gobierno de Lima Independiente. (1822). № 45. Gobierno Legítimo del Perú, Cuzco.

Vargas, N. (1903). Historia del Perú Independiente. Lima: Imprenta de la escuela de Ingenieros.

Vargas, R. (1932). Insurrección de Tacna y Tarapacá: nuevos documentos. Revista de la Universidad Católica, 1 (1).

Vidaurre, M. de. (1971). Memorias y dictámenes, en Los ideólogos, vol. 5, colección documental de la Independencia del Perú, t. I. Lima: ed. Alberto Tauro. 